\title{
Literature Review of the Role of Ultrasound, Computed Tomography, and Transcatheter Arterial Embolization for the Treatment of Traumatic Splenic Injuries
}

\author{
Cornelis H. van der Vlies • Otto M. van Delden • \\ Bastiaan J. Punt $\cdot$ Kees J. Ponsen · Jim A. Reekers • \\ J. Carel Goslings
}

Received: 7 December 2009/ Accepted: 14 June 2010/Published online: 29 July 2010

(C) The Author(s) 2010. This article is published with open access at Springerlink.com

\begin{abstract}
Introduction The spleen is the second most frequently injured organ following blunt abdominal trauma. Trends in management have changed over the years. Traditionally, laparotomy and splenectomy was the standard management. Presently, nonoperative management (NOM) of splenic injury is the most common management strategy in hemodynamically stable patients. Splenic injuries can be managed via simple observation (OBS) or with angiography and embolization (AE). Angio-embolization has shown to be a valuable alternative to observational management and has increased the success rate of nonoperative management in many series.

Diagnostics Improved imaging techniques and advances in interventional radiology have led to a better selection of patients who are amenable to nonoperative management.
\end{abstract}

C. H. van der Vlies $(\bowtie)$. K. J. Ponsen · J. C. Goslings

Trauma Unit, Department of Surgery, Academic Medical Center, Meibergdreef 9, 1105 AZ Amsterdam, The Netherlands

e-mail: c.h.vandervlies@amc.nl

\section{K. J. Ponsen}

e-mail: k.j.ponsen@amc.nl

J. C. Goslings

e-mail: j.c.goslings@amc.nl

O. M. van Delden · J. A. Reekers

Department of Radiology, Academic Medical Center,

Amsterdam, The Netherlands

e-mail: o.m.vandelden@amc.nl

\section{J. A. Reekers}

e-mail: j.a.reekers@amc.nl

\section{B. J. Punt}

Department of Surgery, Albert Schweitzer Hospital, Dordrecht,

The Netherlands

e-mail: b.j.punt@asz.nl
Despite this, there is still a lot of debate about which patients are prone to NOM.

Angiography and Embolization The optimal patient selection is still a matter of debate and the role of CT and angio-embolization has not yet fully evolved. We discuss the role of sonography and CT features, such as contrast extravasation, pseudoaneurysms, arteriovenous fistulas, or hemoperitoneum, to determine the optimal patient selection for angiography and embolization. We also review the efficiency, technical considerations (proximal or selective embolization), logistics, and complication rates of $\mathrm{AE}$ for blunt traumatic splenic injuries.

Keywords Spleen - Nonoperative management . Diagnostics · Angiography and embolization

\section{Introduction}

The spleen is after the liver as the second most frequently injured organ following abdominal trauma, occurring in $32 \%$ of abdominal injuries [1]. Splenic injuries most often are observed in blunt abdominal trauma, such as in motorcycle accidents, assaults, fall from height, and sports. During the past two decades, major changes in the management of splenic injuries have occurred. Traditionally, operative management (OM) was the standard for patients with splenic injury. Once the spleen has been mobilized, a decision must be made regarding splenectomy or splenic salvage procedures (mesh splenorrhaphy, partial resection, adhesive and/or coagulation techniques). Due to the increased risk of infections, in particular fatal overwhelming postsplenectomy sepsis, a trend from splenectomy toward splenic conservation has emerged [2-6]. Presently, nonoperative management (NOM) of splenic injury is the most common 
management strategy in hemodynamically stable patients [7-13]. NOM can be divided as observation (OBS) or angiography and embolization (AE). Observational management involves admission to a unit with monitoring of vital signs, strict bed rest, frequent monitoring of red blood cell count, and serial abdominal examinations [12, 14]. Improved imaging techniques and advances in interventional radiology have helped to differentiate patients who can be observed versus those who need AE. Nevertheless, the optimal patient selection is still a matter of debate and the role of CT and angio-embolization has not yet fully evolved.

The purpose of this article was to review the current literature pertaining to the diagnosis and transcatheter therapy of traumatic splenic injuries.

\section{Diagnostics}

\section{FAST}

The primary goal in the initial management of abdominal trauma is to detect and treat life-threatening injuries, in the majority of cases bleeding-related, as quickly as possible. The method of choice for rapid evaluation of the abdomen for free fluid is the Focused Abdominal Sonography for Trauma (FAST). In European trauma centers, sonography has replaced diagnostic peritoneal lavage as the primary screening test for intra-abdominal hemorrhage. FAST can be performed simultaneously with resuscitation efforts during the initial trauma management and only takes 2 minutes to perform. For this reason, it also is useful in hemodynamically unstable patients [15]. FAST is especially useful for detecting the presence or absence of a hemoperitoneum, a herald of significant organ injury [16-18] with a sensitivity of $90-93 \%$ [19]. However, FAST has a low sensitivity for detecting and grading splenic injury. Injuries to bowel and mesentery without hemoperitoneum and retroperitoneal hematomas also may be missed by FAST [20]. In addition to this, FAST is unable to detect the presence of active hemorrhage. For patients who are hemodynamically stable, a FAST detecting hemoperitoneum should lead to a CT scan for further evaluation of the nature and extent of injury.

When the FAST is negative for hemoperitoneum, debate exists regarding whether a CT scan is required. Estimates for the presence of intra-abdominal injuries in the absence of hemoperitoneum on FAST can be as high as $29 \%$ $[16,21-23]$.

Most trauma centers that use FAST as a primary screening modality rely on the assumption that any missed injuries are low-grade lesions without serious clinical consequence [24, 25]. However, some studies demonstrated that the use of FAST examination as a screening tool for blunt abdominal injury in the hemodynamically stable trauma patient results in underdiagnoses of intraabdominal injuries. Routine CT scan frequently reveals additional injuries, which results in a change of treatment in $6.4-16 \%$ of these patients. [20, 26-28] This may have an impact on treatment and outcome in trauma patients. Therefore, hemodynamically stable patients with a negative FAST and a high clinical suspicion for splenic injury, for example, a seat belt sign or upper abdominal pain, should undergo routine CT scanning.

\section{Computed tomography and grading systems}

CT before and during the arterial and delayed phase of intravenous contrast enhancement is now considered the "gold standard" for diagnosing splenic injuries after trauma and is preferred in hemodynamically stable patients.

$\mathrm{CT}$ is the most accurate test to assess the grade of injury to the spleen, as well as other intraperitoneal and retroperitoneal organs, and it can give a relatively accurate estimation of the volume of hemoperitoneum. It also can detect the presence and location of active arterial hemorrhage as well as the presence of pseudoaneurysms or arteriovenous fistulas in the spleen [29,30]. Active contrast extravasation is usually seen on CT scan as an irregular or linear area of contrast extravasation in the splenic parenchyma (patient A; Fig. 1), subcapsular space or in the peritoneum (patient B; Fig. 2) [28]. It may be difficult to accurately distinguish pseudoaneurysms from extravasation if monophasic scanning is performed during CT. If multiphasic CT is done, washout from the false aneurysm in the delayed phase enables reliable differentiation from extravasation [31].

CT can play a role in hemodynamically unstable patients when the logistic situation is organized in such a way that $\mathrm{CT}$ scanning during initial trauma resuscitation

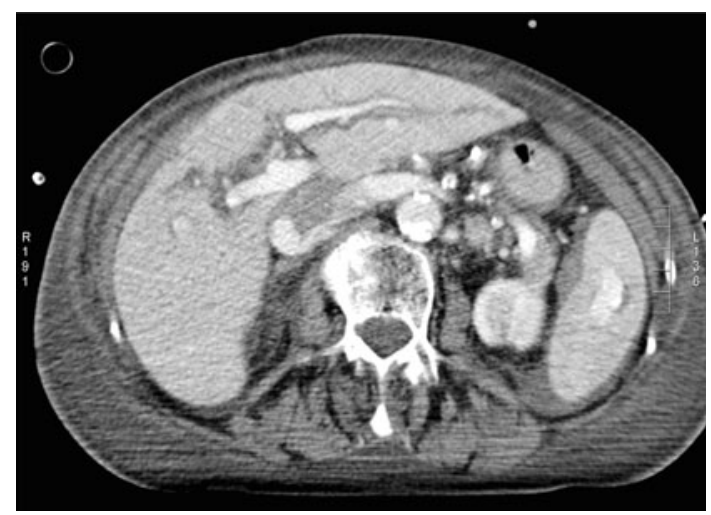

Fig. 1 Hemodynamically stable patient (patient A) with blunt abdominal trauma after fall from horse. CT with intravenous contrast shows small amount of hemoperitoneum around the spleen and a contrast "blush," which is confined to the splenic parenchyma (AAST grade 3 , Baltimore grade 4 a) 


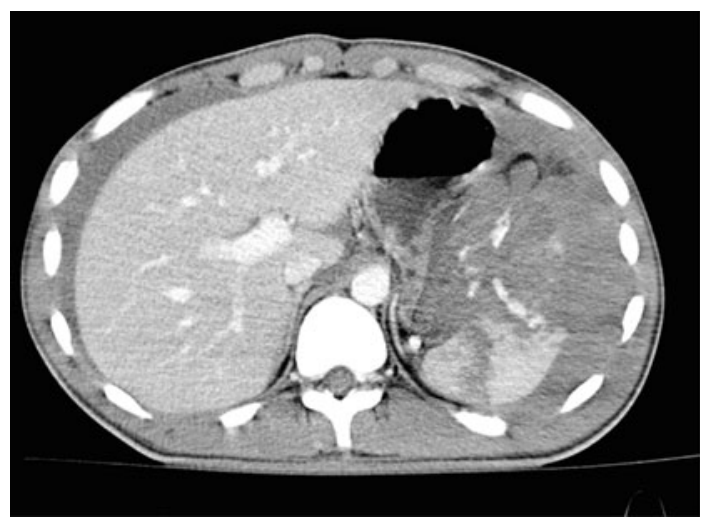

Fig. 2 Hemodynamically stable patient (patient B) with blunt abdominal trauma after motor vehicle accident. CT with intravenous contrast shows hemoperitoneum, fractured spleen with large hematoma and extravasation of contrast medium into the abdominal cavity (AAST grade 4 , Baltimore grade $4 \mathrm{~b}$ )

and evaluation is directly available in or very close to the emergency room $[32,33]$. Limitations of the early trauma CT include its modest sensitivity for assessing injury to pancreas, bowel and mesentery, as well as its relative inability to detect venous hemorrhage.

The most widely used grading system for blunt splenic injuries is the American Association for the Surgery of Trauma (AAST) injury scale $[34,35]$. This grading system (Table 1) is based on the anatomic extension of disruption of the spleen, as shown on CT scans or during laparotomy. However, this grading system is not reliable for the prediction of the outcome of splenic injuries and not decisive about whether surgery of conservative treatment should be applied [2, 36-39].

Previous studies have shown that the CT injury grade alone is a poor predictor for the success of NOM [36, 40, 41].
Recent literature has suggested that vascular injuries, including active splenic bleeding (contrast blush), pseudoaneurysms, and posttraumatic arteriovenous fistulas, are associated with an increased failure rate of nonoperative management [7, $10,13,28,38,42-44]$. However, these injuries are not included in the AAST grading system. Because of the risk of failure of nonoperative management of patients with these injuries on CT scan, it is important to identify these vascular injuries. Marmery and colleagues [45] have developed a new grading system ("Baltimore" grading system) (Table 1), which was based on experience from multiple trauma centers, indicating that $\mathrm{CT}$ evidence of a contrast blush or vascular injuries predicts the need for $\mathrm{AE}$ or surgical management $[28,38,43,46]$. Patients with grade 4 injuries are candidates for splenic arteriography or splenic surgery. This "Baltimore" CT grading system seems to be better than the AAST system for predicting which patients are the most likely candidates for embolization or splenic surgery [45]. However, prospective, randomized studies are needed to validate these results.

\section{Angiography and embolization}

\section{Indications}

In 1995, Sclafani et al. described the first successful use of AE for hemodynamically stable patients with a splenic injury as adjunct to observational management [47]. Since the late 1990s, AE has been applied more frequently to achieve better splenic salvage rates for the treatment of patients with splenic injuries. Simple observation alone has been reported to have a failure rate as high as $34 \%$; the rate is even higher among patients with high-grade splenic injuries (AAST grade III-V) [10, 37, 48-51].

Table 1 Splenic trauma grading systems [34, 35, 45]

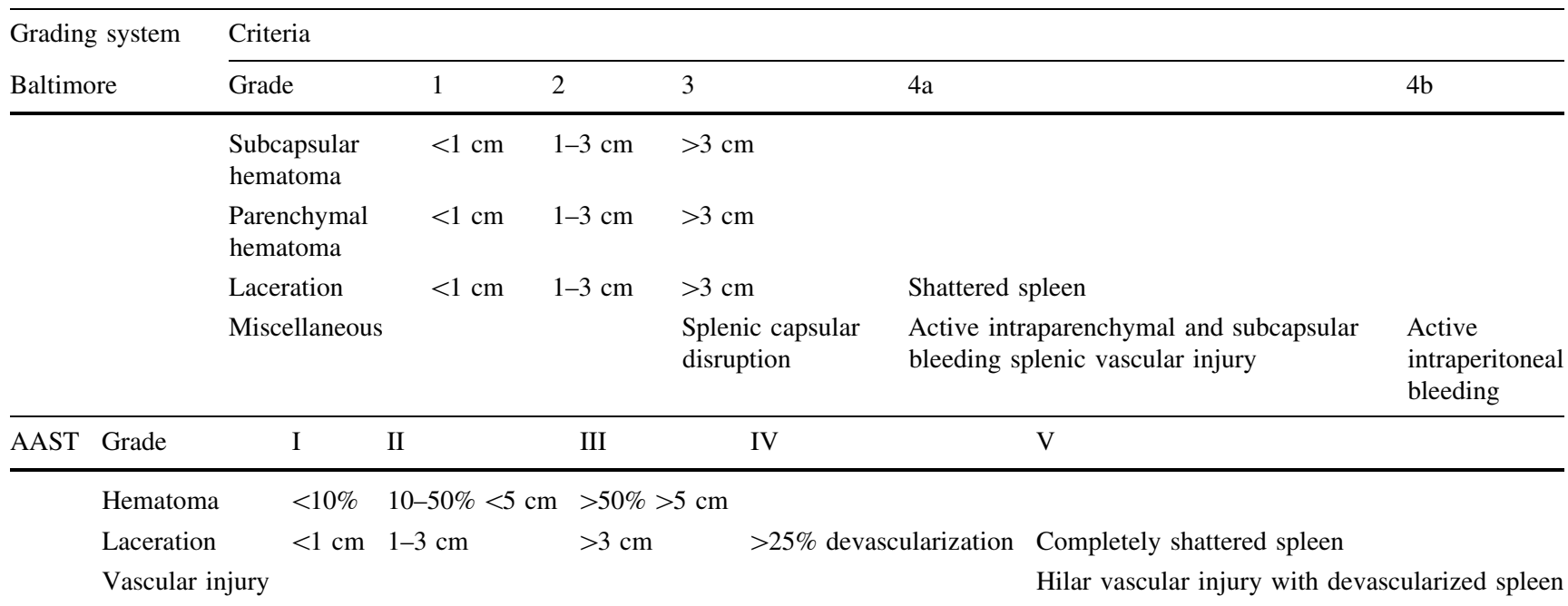


Many studies support the use of embolization as an adjunct to observation. AE has increased the success rate of nonoperative management by stopping ongoing bleeding as well as by preventing delayed rupture of the spleen [7, 47, 52-57]. Success rates up to $97 \%$ are described in the literature. However, these results must be interpreted with some caution, because these results are based on cohort studies, which were compared with results of historical studies. Prospective, randomized, controlled trials have never been published.

Recent studies advocate the use of AE in the presence of the following CT findings: active contrast extravasation, pseudoaneurysm or arteriovenous fistula, large hemoperitoneum, and a higher grade of injury (grade III-V) [9, 10, 23, 28, 49, 55, 58-62].

Several authors and the clinical practical guideline for the NOM of blunt splenic injury of the Eastern Association for the Surgery of Trauma suggest that the presence of a contrast blush or vascular injury on the CT scan may portend a higher failure rate after observational management $[9,10,38,43,46]$.

Schurr et al. [46] described 89 patients who were initially managed nonoperatively. Twelve patients failed NOM. Upon review of the initial computed tomography scans, a contrast blush was noted in 8 of $12(67 \%)$ patients who failed and in 5 of $77(6 \%)$ of those who were successfully managed nonoperatively $(p<0.0001)$. Another study demonstrated that both a contrast blush and traumatic vascular injuries (pseudoaneurysms and arteriovenous fistula) were associated with a high failure rate $(82 \%)$ of nonoperative management [43].

Omert et al. have questioned the significance of a contrast blush. They suggested that a contrast blush is not an absolute indication for an operative or angiographic intervention. Factors, such as patient age, grade of injury, and presence of hypotension, need to be considered in the clinical management of these patients [63].

Splenic embolization has been used successfully in patients with AAST grade 3-5 splenic injuries [9, 10, 55, $59,64]$. Haan et al. published results demonstrating success rates from 87-100\% after embolization [9, 10]. Another study demonstrated increases in NOM success rate from 74-89\% with embolization in patients with high-grade lesions [55].

Presence of a large hemoperitoneum predicted failure of NOM in the EAST study [49] and also in a study by Velmahos et al. [51]. However, in other studies a significant hemoperitoneum did not affect the success rate [9]. The combination of a contrast blush within the peritoneal cavity and a significant hemoperitoneum indicate active and massive bleeding and predict a high failure rate and thus warrant a low threshold for $\mathrm{AE}$ or a splenectomy $[55,61,65]$.
The overall success rate (defined by preservation of the spleen) of splenic embolization ranges from 73-97\% [7, 9, $10,47,54,55,57,58,61,64,66,67]$, with most studies reporting success rates greater than $90 \%$. Several authors also successfully re-embolized patients in whom initial embolization failed, which further increased the splenic salvage rate $[9,58,67]$. Some studies, in contrast, showed no benefit of splenic artery embolization. A study by Harbrecht et al. [68] concluded that patients who underwent splenic arteriography did not have improved nonoperative splenic salvage rates compared with a contemporaneous control group of similarly injured patients. In two other studies, the authors showed their concern that embolization may be overutilized for blunt splenic injury, resulting in still high failure rates $(27 \%)$ after embolization [61, 69]. They recommend a low threshold to operate if bleeding persists in an embolized patient who had the combination of a highgrade injury and large hemoperitoneum or contrast blush on CT. Figure 3 depicts our strategy for the diagnostic and therapeutic management.

\section{Technique}

Splenic arterial catheterization is commonly performed using the common femoral artery access. Placement of a 5- to 6-French introducer sheath suffices in most cases. A flush aortogram may be performed to evaluate anatomy of the visceral vessels but is not mandatory, particularly when a contrast-enhanced CT scan is available. Selective angiography of the splenic artery should always be performed to evaluate arterial injury. Diagnostic series of the splenic artery should be obtained using a 4- or 5-French catheter, but for selective catheterization of splenic artery branches coaxial micro-catheters and micro-guidewires may be required. Techniques and materials used for embolization depend on anatomical considerations, the hemodynamic situation of the patient, and the type and distribution of vascular injuries. Coils are usually the embolic agents of choice, and gelfoam may in some situations be used. Other types of embolic agents are rarely needed. Occasionally, the use of an Amplatzer ${ }^{\circledR}$ vascular plug may be useful [70].

Occlusion after coil embolization usually occurs as a result of coil-induced thrombosis rather than mechanical occlusion of the lumen by the coil and therefore this technique works best when the coagulation profile of the patient is normal or only mildly abnormal. In case of serious clotting disturbances, addition of another embolic agent, such as gelfoam, is indicated. Gelfoam is a sterile gelatin sponge intended for use as a temporary intravascular embolic material. It can be used in the shape of a "torpedo" or as pledgets. It can be injected through both standard 4- to 5-French angiographic catheters and microcatheter systems. The major advantage of coils compared with 


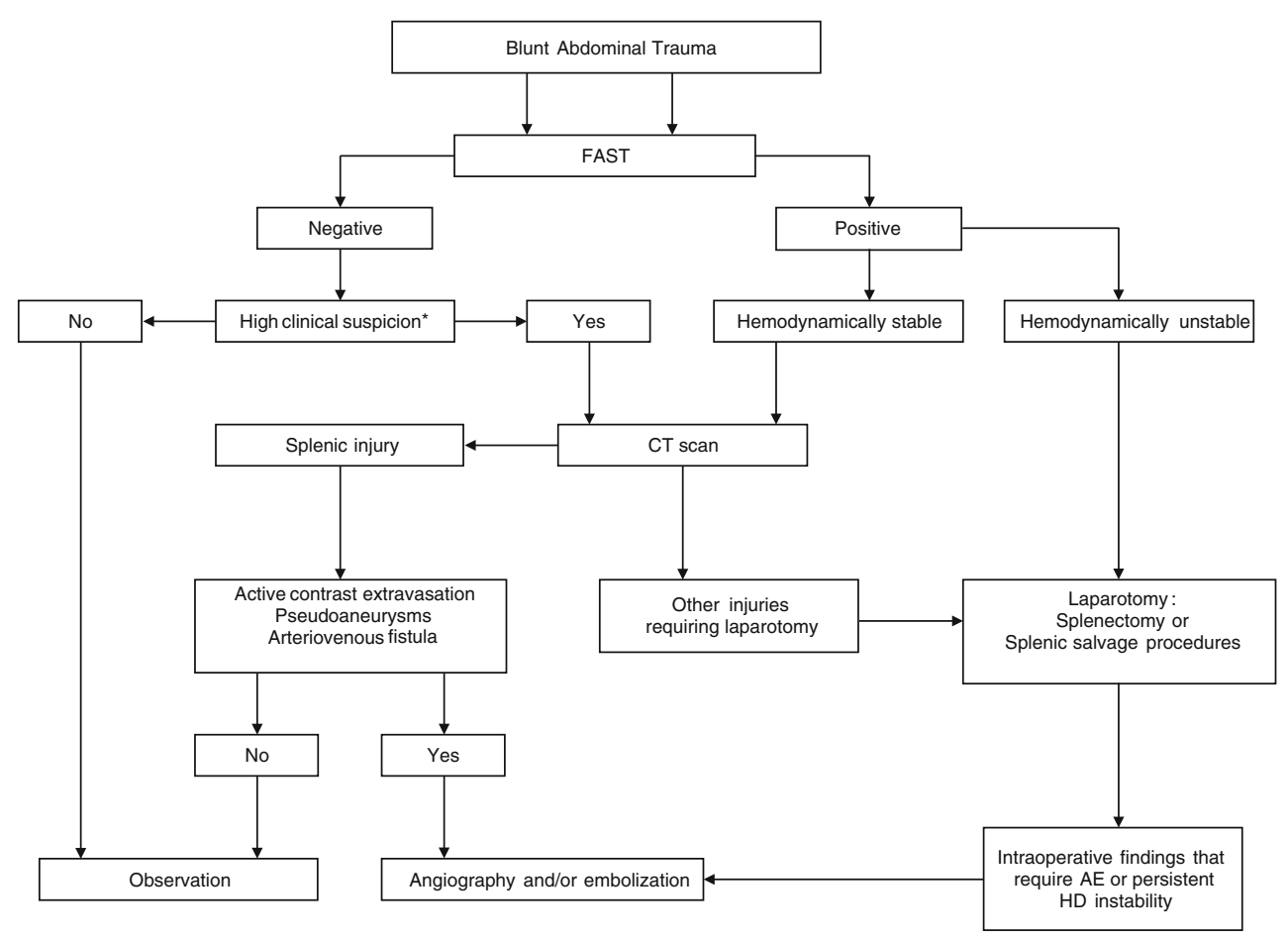

Fig. 3 Flowchart for the diagnostic and therapeutic management of blunt splenic injury. *Abnormalities in physical examination of the abdomen, pelvis, or lumbar spine, base excess $<-3$, systolic blood pressure $<90 \mathrm{mmHg}$, long bone fractures [27]

gelfoam is the ability to provide permanent embolization, which is most desirable in treating vascular injuries. Gelfoam is a biodegradable material, but splenic artery recanalization rates after embolization are not known. However, occlusive agents, such as gelfoam, seem to have a higher failure rate $(50 \%)$ compared with coil embolization $(23 \%)$ [61]. The routine use of antibiotic prophylaxis for splenic artery embolization is not indicated.

\section{Proximal versus Selective Embolization}

Both proximal splenic artery embolization (PSAE) and selective distal splenic artery embolization have been applied and are described in the literature [10, 47]. The surgical equivalent of PSAE for splenic injury-splenic artery ligation-was first described in 1979 [71]. PSAE (patient A; Figs. 4 and 5) is based on the theory that the intrasplenic blood flow and blood pressure decrease, as a result of which the bleeding stops [72]. Sufficient perfusion of the spleen for salvage of the organ is preserved through the collateral flow of the short gastric arteries. PSAE involves occluding the proximal splenic artery using coils or, in some specific situations, using the Amplatzer ${ }^{\circledR}$ vascular plug. It often can be performed using standard 4- to 5-French catheters and is usually less time-consuming than distal embolization [73, 74]. The technique of selective distal embolization (patient B; Figs. 6 and 7) involves

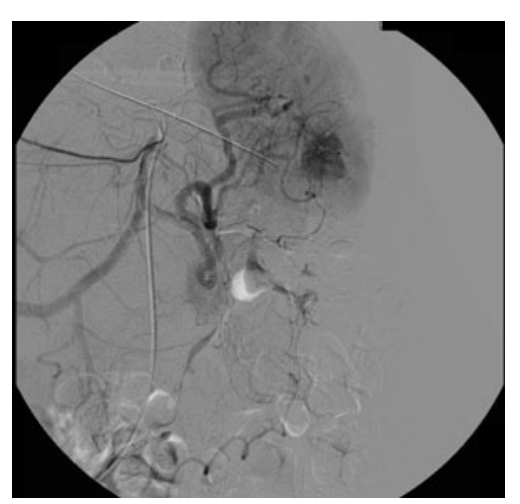

Fig. 4 Same patient (patient A) as in Fig. 1. Selective digital subtraction angiogram of the celiac axis showing the intraparenchymal contrast "blush" in the spleen. Note tortuous anatomy of the splenic artery

embolizing only the injured blood vessels. This often involves smaller branches of the splenic artery, which are inside the spleen itself. Typically a micro-catheter system is required for this type of embolization, particularly when there is significant tortuosity of the splenic artery.

Proximal embolization is mostly used when there is diffuse bleeding of the spleen, when there are multiple focal bleeding vessels in the spleen, when there is timepressure as a result of the hemodynamic situation of the patient, or when tortuosity of the splenic artery prevents selective distal embolization. PSAE also may used in some 


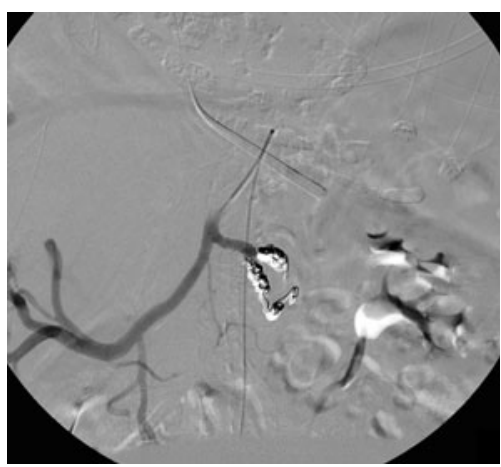

Fig. 5 Same patient (patient A) as Figs. 1 and 4. Selective embolization was not possible as a result of the tortuous anatomy and proximal coil embolization of the splenic artery was performed. Check angiogram after embolization shows occlusion of the proximal splenic artery. Perfusion of the spleen by collaterals is not shown in this image

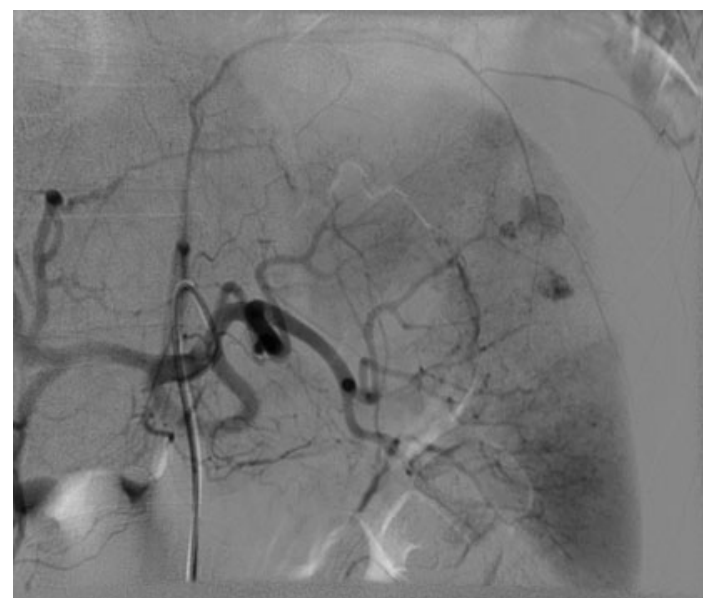

Fig. 6 Same patient (patient B) as in Fig. 2. Selective digital subtraction angiogram of the celiac axis showing multiple areas of contrast extravasation from peripheral branches of the splenic artery

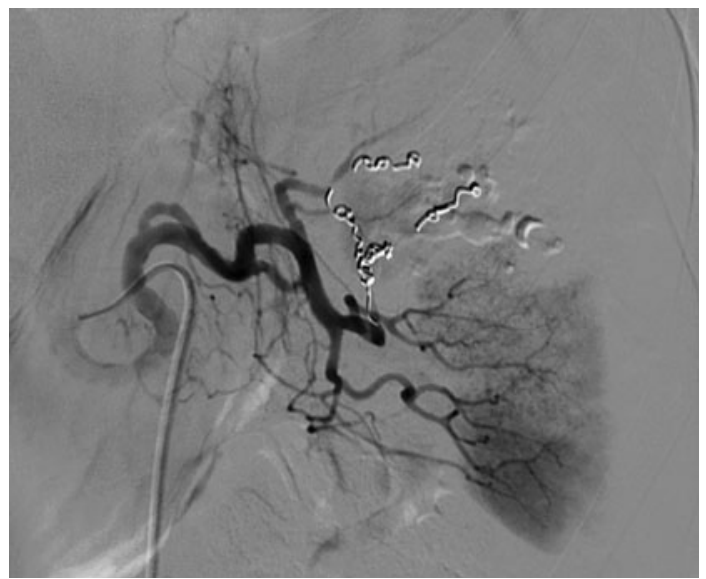

Fig. 7 Same patient (patient B) as in Figs. 2 and 6. Check angiogram after selective coil embolization of an interpolar branch of the splenic artery. Contrast extravasation is no longer seen, and there is good perfusion of the remainder of the spleen situations where the site of hemorrhage is not identified on the angiogram and the clinical situation of the patient suggests ongoing bleeding form the spleen.

Selective distal embolization is usually reserved for patients who have one or only a few focal bleeding vessels in the spleen and in whom the anatomy and hemodynamic situation allow employment of this.

The current literature provides little evidence whether PSAE or selective embolization is a better treatment. Although no prospective studies comparing the results of proximal or selective embolization are described, the use of PSAE seems to have some advantages. PSAE is faster, is associated with a lower failure rate of NOM in some studies, and a lower incidence of splenic abscess or infarction compared with selective distal embolization [64, 75]. However, it has to be noted that splenic infarcts after selective distal embolization rarely lead to clinical sequelae and splenic abscess can usually be treated percutaneously. Several studies have shown that PSAE and selective embolization have no major long-term impact on the splenic anatomy and immune function [42, 76, 77].

A potential disadvantage of PSAE could be the fact that in case of rebleeding, repeat embolization is difficult due to the inaccessibility of the splenic artery. Nevertheless, both techniques have been used successfully. The choice for either of the two techniques depends on the considerations mentioned above as well as operator preference.

\section{Vaccination}

The lifetime risk of overwhelming postsplenectomy sepsis is $1-2 \%$, with a mortality rate of $33 \%$. For that reason, the current recommendation is to treat patients after splenectomy with $H$. influenzae (Hib), pneumococcal, and meningococcal vaccination [78]. Several studies have shown that proximal ligation of the splenic artery and proximal and selective splenic embolization has no major long-term impact on the splenic anatomy and immune function [42, 76, 77]. Only one recent study suggests that the immunologic profile of embolized patients is reduced to controls. These studies, however, state that large controlled studies will be needed to make definitive vaccination recommendations [79]. We applied vaccination in patients after extensive distal embolization or embolization (proximal or distal) for a shattered spleen.

\section{Logistics}

For effective application of AE as a treatment modality, CT scanning should be available $24 \mathrm{~h}$ per day to triage patients between observation, angio-embolization, and surgery. Early assessment using CT scanning in the emergency 
room may further improve these logistics [80, 81]. Also, the hospital interventional radiology suite and personnel should be set up for rapid response at any time.

The success rate of NOM depends on the time between the initial intake at the emergency room and the $\mathrm{AE}$, as a result of the decreasing clinical condition and coagulation state of the patient [82]. Because embolization can be timeconsuming and there is a risk for hemodynamic deterioration, the patient should be monitored carefully. Therefore, $\mathrm{AE}$ requires good teamwork among the trauma surgeon, the anesthesiologist, and the interventional radiologist.

\section{Complications}

Major complications after splenic artery embolization have been reported in $6-20 \%[9,10,83]$. In a small study by Ekeh and colleagues [69], major complications, such as bleeding, abscess, and contrast nephropathy, occurred in $27 \%$. Minor complications, fever, pleural effusions, and coil migration occurred in 53\%. Other studies have demonstrated lower complication rates [9, 10, 83]. In the Western Trauma Association multi-institutional trial [9], 140 patients underwent proximal and distal embolization and combination of both techniques in 83,48 , and 9 patients, respectively. Mean AAST splenic injury grade was 3.5. The following vascular injuries were seen on the CT scan: hemoperitoneum (59\%), contrast extravasation (44\%), pseudoaneurysm (33\%), and AV fistula (4\%). This trial reported a major complication rate of $20 \%$. These complications included persistent bleeding or rebleeding (11\%), missed injury (3\%), and splenic abscess (4\%). Two percent of the patients had coil migration at the time of angiography, without sequelae in any of these patients. Infarctions after embolization occurred in $21 \%$ of patients in this study. Similar infarction rates have been described in other series $[9,61,75,83]$. In one study, the infarction rate was $100 \%$ after distal embolization and $63 \%$ after proximal embolization [66]. Most patients with splenic infarcts are asymptomatic and could be managed conservatively $[61,66]$. Abscess usually presents at contrastenhanced CT as a hypodens fluid collection with or without air or an air-fluid level. However, the presence of gas in the spleen after embolization is not a specific sign for infection. In general, postembolization splenic abscesses can be treated with percutaneous drainage. Puncture site-related complications (hematoma, dissection, thrombosis) after angiography are relatively rare $[47,66]$.

\section{Conclusions}

$\mathrm{AE}$ is widely accepted for the management of hemodynamically stable patients with splenic injury, due to the improved CT techniques, their direct availability in early trauma management, and the advances in interventional radiology. CT scanning with IV contrast aids in selecting hemodynamically stable patients for AE, but the optimal patient selection is still controversial. The single CT finding that warrants immediate $\mathrm{AE}$ is a contrast blush within the peritoneal cavity, particularly for patients who are not hemodynamically stable or who have other clinical signs of ongoing bleeding. Other CT features, such as false aneurysm, AV fistula, contrast extravasation contained within the spleen, and the presence of a hemoperitoneum, are associated with an increased failure rate of NOM, but whether angio-embolization for such findings increase the success rate of NOM remains a matter of debate.

Angio-embolization has shown to be a valuable adjunct to observational management and has increased the success rate of NOM in many series. PSAE and selective embolization can both be performed and there is currently no evidence favoring either technique. However, these results must be interpreted with caution, because they are based on cohort studies, which were compared with results of historical studies. Prospective, randomized, controlled trials comparing observational management versus embolization have never been published. Although difficult to conduct due to the nature of the trauma population, such trials are needed to further determine the optimal patient selection for $\mathrm{AE}$ for traumatic splenic injury.

Conflict of Interest Statement The authors declare that they have no conflict of interest.

Open Access This article is distributed under the terms of the Creative Commons Attribution Noncommercial License which permits any noncommercial use, distribution, and reproduction in any medium, provided the original author(s) and source are credited.

\section{References}

1. Smith J, Caldwell E, D'Amours S, Jalaludin B, Sugrue M (2005) Abdominal trauma: a disease in evolution. ANZ J Surg 75:790-794

2. Malangoni MA, Cue JI, Fallat ME, Willing SJ, Richardson JD (1990) Evaluation of splenic injury by computed tomography and its impact on treatment. Ann Surg 211:592-597

3. Gopal V, Bisno AL (1977) Fulminant pneumococcal infections in "normal" asplenic hosts. Arch Int Med 137:1526-1530

4. Holdsworth RJ, Irving AD, Cuschieri A (1991) Postsplenectomy sepsis and its mortality rate: actual versus perceived risks. $\mathrm{Br}$ J Surg 78:1031-1038

5. Pachter HL, Hofstetter SR, Spencer FC (1981) Evolving concepts in splenic surgery: splenorrhaphy versus splenectomy and postsplenectomy drainage: experience in 105 patients. Ann Surg 194: 262-269

6. Pachter HL, Spencer FC, Hofstetter SR, Liang HG, Hoballah J, Coppa GF (1990) Experience with selective operative and nonoperative treatment of splenic injuries in 193 patients. Ann Surg 211:583-589 
7. Davis KA, Fabian TC, Croce MA et al (1998) Improved success in nonoperative management of blunt splenic injuries: embolization of splenic artery pseudoaneurysms. J Trauma 44:1008-1013

8. Frumiento C, Vane DW (2000) Changing patterns of treatment for blunt splenic injuries: an 11-year experience in a rural state. J Pediatr Surg 35:985-988

9. Haan JM, Biffl W, Knudson MM et al (2004) Splenic embolization revisited: a multicenter review. J Trauma 56:542-547

10. Haan JM, Bochicchio GV, Kramer N, Scalea TM (2005) Nonoperative management of blunt splenic injury: a 5-year experience. J Trauma 58:492-498

11. Harbrecht BG, Zenati MS, Ochoa JB et al (2004) Management of adult blunt splenic injuries: comparison between level I and level II trauma centers. J Am Coll Surg 198:232-239

12. Pachter HL, Guth AA, Hofstetter SR, Spencer FC (1998) Changing patterns in the management of splenic trauma: the impact of nonoperative management. Ann Surg 227:708-717

13. Rutledge R, Hunt JP, Lentz CW et al (1995) A statewide, population-based time-series analysis of the increasing frequency of nonoperative management of abdominal solid organ injury. Ann Surg 222:311-322

14. Konstantakos AK, Barnoski AL, Plaisier BR, Yowler CJ, Fallon WF Jr, Malangoni MA (1999) Optimizing the management of blunt splenic injury in adults and children. Surgery 126:805-812

15. Bode PJ, Edwards MJ, Kruit MC, van Vugt AB (1999) Sonography in a clinical algorithm for early evaluation of 1671 patients with blunt abdominal trauma. AJR Am J Roentgenol 172: 905-911

16. Miller MT, Pasquale MD, Bromberg WJ, Wasser TE, Cox J (2003) Not so FAST. J Trauma 54:52-59

17. Stengel D, Bauwens K, Sehouli J et al (2001) Systematic review and meta-analysis of emergency ultrasonography for blunt abdominal trauma. Br J Surg 88:901-912

18. Stengel D, Bauwens K, Sehouli J et al (2005) Emergency ultrasound-based algorithms for diagnosing blunt abdominal trauma. Cochrane Database Syst Rev CD004446

19. Rozycki GS, Ochsner MG, Schmidt JA et al (1995) A prospective study of surgeon-performed ultrasound as the primary adjuvant modality for injured patient assessment. J Trauma 39:492-498

20. Schnuriger B, Kilz J, Inderbitzin D et al (2009) The accuracy of FAST in relation to grade of solid organ injuries: a retrospective analysis of 226 trauma patients with liver or splenic lesion. BMC Med Imaging 9:3

21. Bisharat N, Omari H, Lavi I, Raz R (2001) Risk of infection and death among post-splenectomy patients. J Infect 43:182-186

22. Lentz KA, McKenney MG (1996) Quantitative sensitivity of ultrasound in detecting free intraperitoneal fluid. J Trauma 40: $1052-1054$

23. Shanmuganathan K, Mirvis SE, Sherbourne CD, Chiu WC, Rodriguez A (1999) Hemoperitoneum as the sole indicator of abdominal visceral injuries: a potential limitation of screening abdominal US for trauma. Radiology 212:423-430

24. Boulanger BR, Brenneman FD, McLellan BA, Rizoli SB, Culhane J, Hamilton P (1995) A prospective study of emergent abdominal sonography after blunt trauma. J Trauma 39:325-330

25. Boulanger BR, McLellan BA, Brenneman FD et al (1996) Emergent abdominal sonography as a screening test in a new diagnostic algorithm for blunt trauma. J Trauma 40:867-874

26. Deunk J, Dekker HM, Brink M, Van VR, Edwards MJ, van Vugt AB (2007) The value of indicated computed tomography scan of the chest and abdomen in addition to the conventional radiologic work-up for blunt trauma patients. J Trauma 63:757-763

27. Deunk J, Brink M, Dekker HM et al (2009) Routine versus selective computed tomography of the abdomen, pelvis, and lumbar spine in blunt trauma: a prospective evaluation. J Trauma 66:1108-1117
28. Shanmuganathan K, Mirvis SE, Boyd-Kranis R, Takada T, Scalea TM (2000) Nonsurgical management of blunt splenic injury: use of CT criteria to select patients for splenic arteriography and potential endovascular therapy. Radiology 217:75-82

29. Miller LA, Shanmuganathan K (2005) Multidetector CT evaluation of abdominal trauma. Radiol Clin North Am 43:1079-1095

30. Yao DC, Jeffrey RB Jr, Mirvis SE et al (2002) Using contrastenhanced helical CT to visualize arterial extravasation after blunt abdominal trauma: incidence and organ distribution. AJR Am J Roentgenol 178:17-20

31. Anderson SW, Varghese JC, Lucey BC, Burke PA, Hirsch EF, Soto JA (2007) Blunt splenic trauma: delayed-phase CT for differentiation of active hemorrhage from contained vascular injury in patients. Radiology 243:88-95

32. Goslings JC, van Delden OM (2007) Angiography and embolisation to control bleeding after blunt injury to the abdomen or pelvis. Ned Tijdschr Geneeskd 151:345-352

33. Lin WC, Chen YF, Lin CH et al (2008) Emergent transcatheter arterial embolization in hemodynamically unstable patients with blunt splenic injury. Acad Radiol 15:201-208

34. Moore EE, Shackford SR, Pachter HL et al (1989) Organ injury scaling: spleen, liver, and kidney. J Trauma 29:1664-1666

35. Moore EE, Cogbill TH, Jurkovich GJ, Shackford SR, Malangoni MA, Champion HR (1995) Organ injury scaling: spleen and liver (1994 revision). J Trauma 38:323-324

36. Becker CD, Mentha G, Terrier F (1998) Blunt abdominal trauma in adults: role of CT in the diagnosis and management of visceral injuries. Part 1: liver and spleen. Eur Radiol 8:553-562

37. Brasel KJ, DeLisle CM, Olson CJ, Borgstrom DC (1998) Splenic injury: trends in evaluation and management. J Trauma 44: 283-286

38. Federle MP, Courcoulas AP, Powell M, Ferris JV, Peitzman AB (1998) Blunt splenic injury in adults: clinical and CT criteria for management, with emphasis on active extravasation. Radiology 206:137-142

39. Mirvis SE, Whitley NO, Gens DR (1989) Blunt splenic trauma in adults: CT-based classification and correlation with prognosis and treatment. Radiology 171:33-39

40. Kohn JS, Clark DE, Isler RJ, Pope CF (1994) Is computed tomographic grading of splenic injury useful in the nonsurgical management of blunt trauma? J Trauma 36:385-389

41. Sutyak JP, Chiu WC, D'Amelio LF, Amorosa JK, Hammond JS (1995) Computed tomography is inaccurate in estimating the severity of adult splenic injury. J Trauma 39:514-518

42. Bessoud B, Duchosal MA, Siegrist CA et al (2007) Proximal splenic artery embolization for blunt splenic injury: clinical, immunologic, and ultrasound-Doppler follow-up. J Trauma 62:1481-1486

43. Gavant ML, Schurr M, Flick PA, Croce MA, Fabian TC, Gold RE (1997) Predicting clinical outcome of nonsurgical management of blunt splenic injury: using CT to reveal abnormalities of splenic vasculature. AJR Am J Roentgenol 168:207-212

44. Shanmuganathan K (2004) Multi-detector row CT imaging of blunt abdominal trauma. Semin Ultrasound CT MR 25:180-204

45. Marmery H, Shanmuganathan K, Alexander MT, Mirvis SE (2007) Optimization of selection for nonoperative management of blunt splenic injury: comparison of MDCT grading systems. AJR Am J Roentgenol 189:1421-1427

46. Schurr MJ, Fabian TC, Gavant M et al (1995) Management of blunt splenic trauma: computed tomographic contrast blush predicts failure of nonoperative management. J Trauma 39: 507-512

47. Sclafani SJ, Shaftan GW, Scalea TM et al (1995) Nonoperative salvage of computed tomography-diagnosed splenic injuries: utilization of angiography for triage and embolization for hemostasis. J Trauma 39:818-825 
48. Cogbill TH, Moore EE, Jurkovich GJ et al (1989) Nonoperative management of blunt splenic trauma: a multicenter experience. J Trauma 29:1312-1317

49. Peitzman AB, Heil B, Rivera L et al (2000) Blunt splenic injury in adults: multi-institutional study of the Eastern association for the surgery of Trauma. J Trauma 49:177-187

50. Sharma OP, Oswanski MF, Singer D, Raj SS, Daoud YA (2005) Assessment of nonoperative management of blunt spleen and liver trauma. Am Surg 71:379-386

51. Velmahos GC, Toutouzas KG, Radin R, Chan L, Demetriades D (2003) Nonoperative treatment of blunt injury to solid abdominal organs: a prospective study. Arch Surg 138:844-851

52. Haan J, Bochicchio G, Kramer M, Scalea T (2003) Air following splenic embolization: infection or incidental finding? Am Surg 69:1036-1039

53. Haan JM, Boswell S, Stein D, Scalea TM (2007) Follow-up abdominal CT is not necessary in low-grade splenic injury. Am Surg 73:13-18

54. Hagiwara A, Yukioka T, Ohta S, Nitatori T, Matsuda H, Shimazaki S (1996) Nonsurgical management of patients with blunt splenic injury: efficacy of transcatheter arterial embolization. AJR Am J Roentgenol 167:159-166

55. Liu PP, Lee WC, Cheng YF et al (2004) Use of splenic artery embolization as an adjunct to nonsurgical management of blunt splenic injury. J Trauma 56:768-772

56. Myers JG, Dent DL, Stewart RM et al (2000) Blunt splenic injuries: dedicated trauma surgeons can achieve a high rate of nonoperative success in patients of all ages. J Trauma 48: 801-805

57. Sclafani SJ, Weisberg A, Scalea TM, Phillips TF, Duncan AO (1991) Blunt splenic injuries: nonsurgical treatment with CT, arteriography, and transcatheter arterial embolization of the splenic artery. Radiology 181:189-196

58. Dent D, Alsabrook G, Erickson BA et al (2004) Blunt splenic injuries: high nonoperative management rate can be achieved with selective embolization. J Trauma 56:1063-1067

59. Haan J, Ilahi ON, Kramer M, Scalea TM, Myers J (2003) Protocol-driven nonoperative management in patients with blunt splenic trauma and minimal associated injury decreases length of stay. J Trauma 55:317-321

60. Rajani RR, Claridge JA, Yowler CJ et al (2006) Improved outcome of adult blunt splenic injury: a cohort analysis. Surgery 140:625-631

61. Smith HE, Biffl WL, Majercik SD, Jednacz J, Lambiase R, Cioffi WG (2006) Splenic artery embolization: have we gone too far? J Trauma 61:541-544

62. Wei B, Hemmila MR, Arbabi S, Taheri PA, Wahl WL (2008) Angioembolization reduces operative intervention for blunt splenic injury. J Trauma 64:1472-1477

63. Omert LA, Salyer D, Dunham CM, Porter J, Silva A, Protetch J (2001) Implications of the "contrast blush" finding on computed tomographic scan of the spleen in trauma. J Trauma 51:272-277

64. Bessoud B, Denys A, Calmes JM et al (2006) Nonoperative management of traumatic splenic injuries: is there a role for proximal splenic artery embolization? AJR Am J Roentgenol 186:779-785

65. Fang JF, Chen RJ, Wong YC et al (2000) Classification and treatment of pooling of contrast material on computed tomographic scan of blunt hepatic trauma. J Trauma 49:1083-1088

66. Haan J, Scott J, Boyd-Kranis RL, Ho S, Kramer M, Scalea TM (2001) Admission angiography for blunt splenic injury: advantages and pitfalls. J Trauma 51:1161-1165
67. Haan JM, Marmery H, Shanmuganathan K, Mirvis SE, Scalea TM (2007) Experience with splenic main coil embolization and significance of new or persistent pseudoaneurysm: re-embolize, operate, or observe. J Trauma 63:615-619

68. Harbrecht BG, Ko SH, Watson GA, Forsythe RM, Rosengart MR, Peitzman AB (2007) Angiography for blunt splenic trauma does not improve the success rate of nonoperative management. J Trauma 63:44-49

69. Duchesne JC, Simmons JD, Schmieg RE Jr, McSwain NE Jr, Bellows CF (2008) Proximal splenic angioembolization does not improve outcomes in treating blunt splenic injuries compared with splenectomy: a cohort analysis. J Trauma 65:1346-1351

70. Widlus DM, Moeslein FM, Richard HM III (2008) Evaluation of the Amplatzer ${ }^{\circledR}$ vascular plug for proximal splenic artery embolization. J Vasc Interv Radiol 19(5):652-656

71. Keramidas DC (1979) The ligation of the splenic artery in the treatment of traumatic rupture of the spleen. Surgery 85:530-533

72. Bessoud B, Denys A (2004) Main splenic artery embolization using coils in blunt splenic injuries: effects on the intrasplenic blood pressure. Eur Radiol 14:1718-1719

73. Anderson JH, VuBan A, Wallace S, Hester JP, Burke JS (1977) Transcatheter splenic arterial occlusion: an experimental study in dogs. Radiology 125:95-102

74. Keramidas DC, Kelekis D, Dolatzas T, Aivazoglou T, Voyatzis N (1984) The collateral arterial network of the spleen following ligation of the splenic artery in traumatic rupture of the spleen; an arteriographic study. Z Kinderchir 39:50-51

75. Killeen KL, Shanmuganathan K, Boyd-Kranis R, Scalea TM, Mirvis SE (2001) CT findings after embolization for blunt splenic trauma. J Vasc Interv Radiol 12:209-214

76. Tominaga GT, Simon FJ Jr, Dandan IS et al (2009) Immunologic function after splenic embolization, is there a difference? J Trauma 67:289-295

77. Falimirski M, Syed A, Prybilla D (2007) Immunocompetence of the severely injured spleen verified by differential interference contrast microscopy: the red blood cell pit test. J Trauma 63(5): 1087-1091

78. Davies JM, Barnes R, Milligan D (2002) Update of guidelines for the prevention and treatment of infection in patients with an absent or dysfunctional spleen. Clin Med 2(5):440-443

79. Nakae H, Shimazu T, Miyauchi H, Morozumi J, Ohta S, Yamaguchi Y, Kishikawa M, Ueyama M, Kitano M, Ikeuchi H, Yukioka T, Sugimoto H (2009) Does splenic preservation treatment (embolization, splenorrhaphy, and partial splenectomy) improve immunologic function and long-term prognosis after splenic injury? J Trauma 67(3):557-563

80. Huber-Wagner S, Lefering R, Qvick LM et al (2009) Effect of whole-body CT during trauma resuscitation on survival: a retrospective, multicentre study. Lancet 373:1455-1461

81. Saltzherr TP, Fung Kon Jin PH, Bakker FC et al (2008) An evaluation of a Shockroom located CT scanner: a randomized study of early assessment by CT scanning in trauma patients in the bi-located trauma center North-West Netherlands (REACT trial). BMC Emerg Med 8:10

82. Agolini SF, Shah K, Jaffe J, Newcomb J, Rhodes M, Reed JF III (1997) Arterial embolization is a rapid and effective technique for controlling pelvic fracture hemorrhage. J Trauma 43:395-399

83. Ekeh AP, McCarthy MC, Woods RJ, Haley E (2005) Complications arising from splenic embolization after blunt splenic trauma. Am J Surg 189:335-339 